\title{
||||||||||||||||||||||||||||||||||||||||||||||||||||||||||||||||||.
}

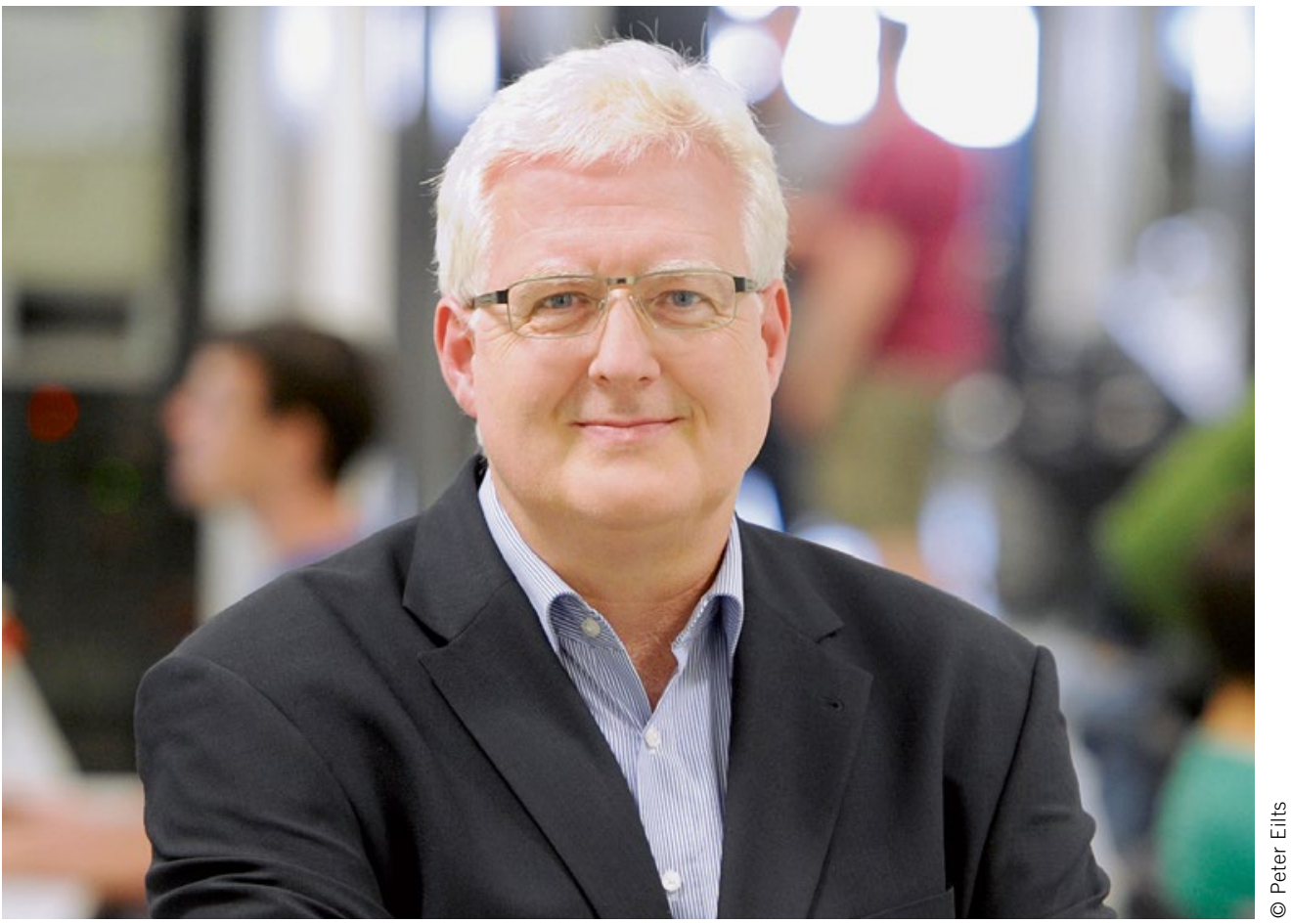

Prof. Dr.-Ing. Peter Eilts Head of the Institute of Internal Combustion Engines (ivb) of the Technische Universität Braunschweig (Germany)

\section{Future of the Internal Combustion Engine}

The internal combustion engine will remain an indispensable part of the majority of off-road applications in the foreseeable future. However, it must respond to two major challenges: the reduction of $\mathrm{CO}_{2}$ and pollutant emissions. To date, $\mathrm{CO}_{2}$ emissions have not been limited in the off-road sector. However, corresponding regulations are expected to be introduced. The emission of $\mathrm{CO}_{2}$ is directly linked with fuel consumption. This has always played a key role in off-road applications because fuel costs account for the largest proportion of life cycle costs. For this reason alone, achieving high efficiency for the powertrain is a central development objective.

Potential for improving efficiency is certainly still offered by the internal combustion engine. In addition to optimised working processes with higher peak pressures, a great deal can be achieved by turbocharging. In particular, the efficiency of the turbocharger plays a very important role. The turbochargers found in most off-road engines are those used in HGVs, and their efficiency is relatively poor. Together with higher turbocharger efficiencies, considerable improvements in efficiency can be also be achieved by using turbo compounding. Other approaches include the use of variable valve timing and the reduction of friction.

In parallel to improving efficiency, $\mathrm{CO}_{2}$ emissions can also be reduced by the use of alternative fuels. Natural gas, for example, offers a promising opportunity. Due to its more favourable $\mathrm{C} / \mathrm{H}$ ratio compared to liquid fuels, the $\mathrm{CO}_{2}$ emission of natural gas is around $20 \%$ lower. The main development objective here is to minimise methane slip. Alternative biogenic liquid fuels, some of which have a much greater $\mathrm{CO}_{2}$ reduction potential, are not currently competitive for cost reasons.

The other major area is pollutant emissions. EU Stage V is just around the corner, and it demands the same limitation of particle numbers that has already been introduced for cars and heavy goods vehicles. This will require a closed diesel particulate filter. In addition, the measurement of Real Driving Emissions for offroad applications is already being widely discussed.

Off-road vehicles - depending on where they are being used - are often driven in the part-load range for a longer period, and the overall system of the engine and exhaust aftertreatment must be designed accordingly. Furthermore, the package requires considerable design expertise. And finally, the consumption of urea in SCR applications also needs to be taken into consideration, as it is included in the operating costs. A suitable selection of the engine settings can help to minimise this consumption.

Therefore, the internal combustion engine still has solid development potential for mastering the current demanding challenges. We will be able to discuss many of these issues at the International MTZ Conference on Heavy-Duty On- and Off-Highway Engines in November. I am looking forward to this opportunity. 